BMJ Surgery, Interventions, \& Health Technologies

\section{Evaluation of reoperations for removal of bioabsorbable plates and screws based on adverse events reports from PMDA, Japan}

\author{
Tomoko Kobayashi (D) , ${ }^{1}$ Nobuhiro Handa (D) , ${ }^{2}$ Kazuhisa Koike, ${ }^{3}$ \\ Shuichi Mochizuki, ${ }^{2}$ I Kaku, ${ }^{2}$ Shinichi Takae ${ }^{2}$
}

To cite: Kobayashi T, Handa N, Koike K, et al. Evaluation of reoperations for removal of bioabsorbable plates and screws based on adverse events reports from PMDA, Japan. BMJ Surg Interv Health Technologies 2020;2:e000033. doi:10.1136/ bmjsit-2020-000033

Received 01 February 2020 Accepted 07 April 2020
Check for updates

(C) Author(s) (or their employer(s)) 2020. Re-use permitted under CC BY-NC. No commercial re-use. See rights and permissions. Published by BMJ.

${ }^{1}$ Department of Orthopedic Surgery, Japan Community Health Care Organization Tokyo Joto Hospital, Tokyo, Japan

${ }^{2}$ Medical Device Unit,

Pharmaceuticals and Medical Devices Agency, Tokyo, Japan ${ }^{3}$ Office of Manufacturing Quality and Vigilance for Medical Devices, Pharmaceuticals and Medical Devices Agency, Tokyo, Japan

Correspondence to Dr Nobuhiro Handa; handa-nobuhiro@pmda.go.jp
Bioabsorbable plates and screws (BPS) are now widely used as a well-established internal fixation method for various osteosynthetic surgeries, such as fixation of fractures or osteotomies. One of the BPS's main advantages is that surgical removal is unnecessary since they are ostensibly fully absorbed over time. ${ }^{12}$ In fact, to date there have been few reports available focusing on surgical removal of BPS. For example, one large series $(n=1883$ patients) of absorbable plate and screw fixations in pediatric craniofacial surgery confirmed that none of the devices required surgical removal. ${ }^{3}$ Another review article, assessing 19 papers consisting of 438 patients, reported 8-10 cases of implant removal. ${ }^{4}$

In the premarket evaluation by the Pharmaceuticals and Medical Devices Agency (PMDA) of Japan, the effectiveness and safety of BPS have been evaluated in clinical trials which consist of a small number of study subjects with limited follow-up. Still, it is difficult to identify rare adverse events (AEs) before approval, particularly in the late follow-up phase. The PMDA of Japan has adverse events and infections reporting system for medical devices. Marketing authorization holders (MAHs) are obligated to submit an $\mathrm{AE}$ report to the PMDA under the provision of the PMD Act (ie, Law on Securing Quality, Efficacy, and Safety of Products, Including Pharmaceuticals and Medical Devices). The limitations of this system is that if the MAH does not capture the events, then these will not be reported to the PMDA. Hence, the real number of events is likely to be much higher than reported. It is also impossible to identify the denominator (total patient-years of the device used) so that the exact incidence of the events cannot be calculated. Despite these limitations, the $\mathrm{AE}$ reporting system remains critically important for detection of rare events in the late follow-up phase.

To identify and analyze late BPS removal, the AE database of PMDA was searched from October 2003 to July 2016, and a total of 162 cases of BPS removal were identified. Of these, $89(54.9 \%)$ were male and $53(32.7 \%)$ were female, and for $20(12.3 \%)$ cases the gender was unknown. The median age was 30 years (IQR, 43-20 years), and age was not known in $41(25.3 \%)$ cases.

\section{INDICATIONS FOR ORIGINAL SURGERY}

The main reason to use BPS in the original surgery was trauma in $96(59.3 \%)$ cases $(87$ cases for maxillofacial fracture, 9 cases for limb injury). Other surgeries included bone fixation secondary to thoracotomy, open heart surgery or craniotomy in $15(9.3 \%)$ cases; fixation of congenital disease in 13 $(8.0 \%)$ cases; jaw deformity in $12(7.4 \%)$ cases; degenerative disease in $7(4.3 \%)$ cases; tumor in $2(1.2 \%)$ cases; and unknown in 17 $(10.5 \%)$ cases.

\section{AE TIMING AND TYPE}

The intervals between the original surgery and $\mathrm{AE}$ development and the type of $\mathrm{AE}$ are shown in figure 1 . One hundred cases $(61.7 \%)$ occurred within 6 months (ie, 53 cases within 1 month and 47 cases between 1 and 6 months), while $53(32.7 \%)$ cases occurred after 6 months. AEs were constantly reported up to 4.5 years. The main reason for surgical removal within 1 month was either infection or implant failure. In contrast, surgical removal after 6 months was mostly due to either late infection or non-bacterial inflammatory reaction (figure 1 ). 


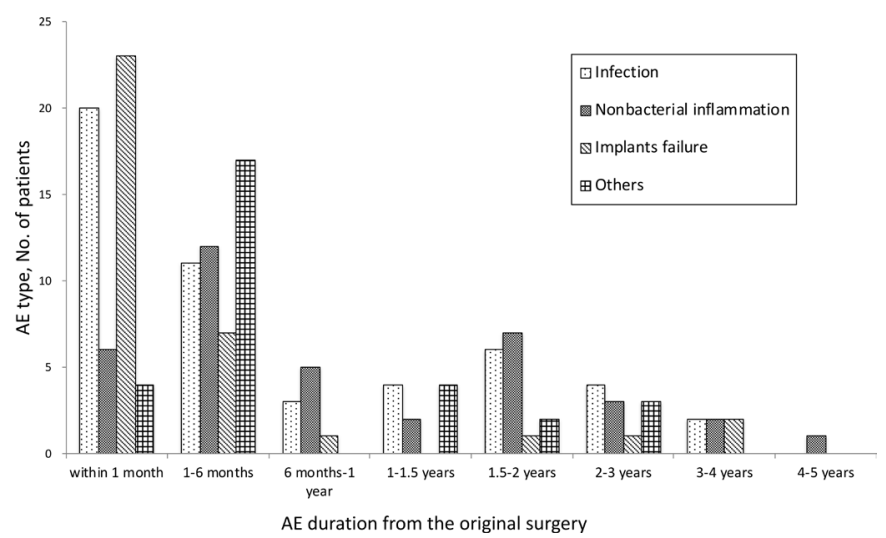

Figure 1 Types of $A E$ and time of onset of $A E$ from the original surgery. A total of 53 cases occurred within 1 month after BPS implantation, and 47 cases from 1 to 6 months post-implantation. Late removal after 6 months was required in $53(32.7 \%)$ cases, mainly due to either late infection (19 cases, $11.7 \%$ ) or non-bacterial inflammation (20 cases, $12.3 \%)$. Infections within 1 month were the most frequent in $20(39.2 \%)$ cases. However, delayed infections after 6 months were also reported in 19 (37.3\%) cases. Nonbacterial inflammations were the most frequent $(20$ cases, $50 \%)$ after 6 months, whereas implant failures were the most frequent ( 23 cases, $57.5 \%$ ) within 1 month. An increase in $\mathrm{AE}$ was observed after 1.5-2 years of implantation. The longest duration post-BPS implantation was found at 4 years and 6 months. AE, adverse event; BPS, bioabsorbable plates and screws.

\section{MATERIALS USED IN IMPLANTS}

The materials used in eight BPS items, consisting of three bioabsorbable plates and five bioabsorbable screws, were as follows: three items consist of poly-L-lactic acid (PLLA); four items of unsintered hydroxyapatite and PLLA; and one item of copolymers of PLLA and polyglycolic acid. There was no significant difference in event occurrence by implant materials.

The present aggregated results lead us to focus on the following several findings. First, late AEs 6 months postimplantation accounted for one-third of them. Second, it is important to note that late phase infection, after 6 months, occurred in 19 cases, which is nearly equal to 20 cases in the acute infection phase, within 1 month. Third, most cases of surgical removal followed BPS implantation in cranial or maxillofacial surgery, which requires reflection. Finally, although speed of absorption differed among the different BPS materials, foreign body reactions are known to occur during a later follow-up phase, approximately between 6 months and 5 years after surgery, ${ }^{145}$ as observed in the study.

Given the results of our study we would like to send the message to surgeons who use BPS that BPS might require surgical removal during a later follow-up period, even after 6 months and up to 4.5 years. Continuous and careful follow-up, especially monitoring for possible infections and non-bacterial inflammations, should be considered as needed. Additionally, patients treated with BPS must be fully informed about the potential AEs that may occur before BPS's complete degradation, as well as the possibility of surgical removal.

Contributors TK and NH designed the study, and TK wrote the initial draft of the manuscript. TK, NH, SM, and KK contributed to analysis and interpretation of data, and assisted in the preparation of the manuscript. All other authors have contributed to data collection and interpretation, and critically reviewed the manuscript. All authors approved the final version of the manuscript, and agree to be accountable for all aspects of the work in ensuring that questions related to the accuracy or integrity of any part of the work are appropriately investigated and resolved.

Funding The authors have not declared a specific grant for this research from any funding agency in the public, commercial or not-for-profit sectors.

Disclaimer The views and opinions expressed in the manuscript are the authors' and do not necessarily reflect the official view of the PMDA.

Competing interests None declared.

Patient consent for publication Not required.

Ethics approval This study was approved by the ethical committee of PMDA .

Provenance and peer review Not commissioned; externally peer reviewed.

Open access This is an open access article distributed in accordance with the Creative Commons Attribution Non Commercial (CC BY-NC 4.0) license, which permits others to distribute, remix, adapt, build upon this work non-commercially, and license their derivative works on different terms, provided the original work is properly cited, appropriate credit is given, any changes made indicated, and the use is non-commercial. See: http://creativecommons.org/licenses/by-nc/4.0/.

ORCID iDs

Tomoko Kobayashi http://orcid.org/0000-0002-0081-9927

Nobuhiro Handa http://orcid.org/0000-0003-2838-6462

\section{REFERENCES}

1 Kanno T, Sukegawa S, Furuki Y, et al. Overview of innovative advances in bioresorbable plate systems for oral and maxillofacial surgery. Jpn Dent Sci Rev 2018;54:127-38.

2 Pina S, Ferreira J. Bioresorbable plates and screws for clinical applications: a review. J Healthc Eng 2012;3:243-60.

3 Eppley BL, Morales L, Wood R, et al. Resorbable PLLA-PGA plate and screw fixation in pediatric craniofacial surgery: clinical experience in 1883 patients. Plast Reconstr Surg 2004;114:850-6.

4 Agarwal S, Gupta A, Grevious M, et al. Use of resorbable implants for mandibular fixation: a systematic review. J Craniofac Surg 2009;20:331-9.

5 Choi SH, Lee JH. Absorbable plate-related infection after facial bone fracture reduction. Arch Craniofac Surg 2016;17:1-4. 